\title{
Editorial
}

\section{Physical Space and the Process of Education}

Physical space plays an important role in our everyday life. It determines us, and at the same time we define it. How these exchanges happen in practice, and why are these transitions are so interesting and useful, are basic questions for researchers and designers. We live, work and learn in premises of the past; we can not be born, teach or work in a place that does not yet exist. Space and time are related and specifically determine us. How the best place for teaching and learning looks, and how it must be designed in order to make these activities more effective and enjoyable, are very interesting questions that require future research. This is why the main purpose of this special issue of CEPS Journal is discussion of the significance of physical space in the educational process. Content areas that can be linked to questions of space are highly significant and at the same time very heterogeneous, as they include concepts of school space from historical, sociological, philosophical, pedagogical, psychological and other viewpoints. We should not forget the influence of physical space on the didactic aspects of the educational process, stressing the dichotomy between virtual and real space in our everyday teaching and learning practice. Furthermore, school is a public physical space that serves the local community, and its formal characteristics express the community's engagement in sustainable development as a positive legacy for future generations.

The main characteristic of the present issue is its distinct interdisciplinary focus. Interdisciplinary work requires openness and dialogue regarding concept definitions, and if some concepts are used interchangeably over time redundant concepts lose territory. One could argue that the concept of space is vague, and encourage the use of more precise words like »dwelling«, »landscape«, »city«, or »neighbourhood«. However, there seems to be a need for a common term for the physical environment in relation to the social, psychological and cultural meanings attached to it. It might be more difficult to see common features in research on different kinds of environments if an umbrella term has not been identified. »Space« is a term that is difficult to replace (Hauge, 2007).

A notion of space turns up in every corner of our consciousness, in language, dance, sports, psychology, sociology, economics - wherever movement is possible - and so is easily applicable on a flat surface. Space as experience has to derive from an ability to imagine a dimension that projects above basic 
reality, an exposure to a reality greater than we are able to conceptualise. The sense of space is a mental construct, a projection of the outside world as we experience it according to the equipment at our disposal: an idea, as H. Hertzberger (2000) says.

Awareness of physical space is thus not a concrete inner experience but a learnt set of activities that we carry out. These activities help us to compare ourselves with the surrounding environment. Our senses and memory play key roles in making spatial comparisons. Identity develops as children learn to differentiate themselves from the people around them, and, in the same way, place-identity develops as a child learns to see herself or himself as distinct from, but related to, the physical environment. Among the first identity determinants are those rooted in the child's experience with toys, clothes and rooms. The home is the environment of primary importance, followed by the neighbourhood and the school. Here, social and environmental skills and relationships are learned, and the »lenses « are formed through which the child will later recognise, evaluate and create places.

A place, a defined portion of physical space, can also be defined as a social entity providing identity. However, the converse is also true: places are also influenced by people's identities. People personalise their homes and workplaces with decorations, so that their houses and gardens reflect and communicate who they are (Korpela, 1989). The physical space of school is also a personalised space that reflects the personality of the teachers, authorities and children that live and work there on an everyday basis.

Environmental images can be analysed in terms of identity, structure and meaning. Efficient images demand distinguishing features. This is called identity. Such images suggest a spatial relationship to the viewer and other objects; they contain practical or emotional significance for the viewer. It is necessary to take into account the physical quality of the elements, which must be significant enough to enable the identification of spatial structure and the functioning of the imagination, or »readability«, »evidence«. As regards the development of the image viewer and the viewed image, there are two poles on which to build: material changes in the environment and leading the viewer to new incentives that may change old images. Places and objects define space and give space "personality«. Space becomes a place when it gets precise definition and meaning (Tuan, 2003). It is also argued that the individual's experiences of spaces are related to memories from childhood, which provide a framework of references that play an important role in the formation of adult identity. The role of school physical space memory is definitely crucial.

Five of the articles in the present interdisciplinary issue of CEPS Journal 
discuss different aspects of physical space and the educational process.

In the article Adapting and Designing Spaces: Children and their Schools, Andrea Kenkmann affirms that in schools children experience their environment on three different levels: firstly, they constantly make spatial decisions by positioning themselves in relation to others and organising their immediate environment; secondly, they contribute to shaping the classroom space; and, thirdly, they are confronted with the designed school as a whole. Children's participation in the school design process on the level of the classroom, where a genuine shared organisation can take place on an everyday use basis, is laudable, as it helps children identify and appropriate space.

In School Buildings for the 21st Century - Some Features of New School Buildings in Iceland by Anna Kristin Sigurdardottir and Torfi Hjartarson there is an attempt to identify features of change in the design of new school buildings in Iceland at the primary and lower secondary level and an analysis of how these changes affect teachers' work. The environmental and architectonic features that characterise recently designed school buildings are examined in light of challenges involving architecture, educational ideology, school policy and digital technology. The article presents a research project that included all of the teachers in twenty new schools and was carried out in order to determine whether teachers' work in new learning environments differs from teachers' work in more traditional classroom settings regarding their general approach to teaching and learning. The results indicate a clear shift in the design of educational buildings. Flexibility, flow, openness, social dynamics and teamwork seem to guide recent school design. Clusters of classrooms or open spaces, transparent or movable boundaries, as well as public spaces allowing for manifold interactions in flexible groups, seem to be replacing traditional classrooms along confining corridors. Teachers working in open classroom environments collaborate more often and their pupils also seem to enjoy more variation regarding group division and workspace arrangements.

In Off to School: A Comparative Study of Schools in the U.S., Eftyhia Theodoropoulos compares the physical structure of two schools with differing socioeconomic backgrounds: one is a private day school servicing the children of some of the most affluent families in one of the biggest urban cities in the southwest, while the other is a technical or vocational high school with the majority of the students living in "economically disadvantaged « homes. This comparative research was done through the use of traditional qualitative methods in addition to the use of photography. The juxtaposition of the photographs of the built environment of the two schools creates a concrete visual manifestation of the differences in the daily experience of the students who attend the 
schools. The visible differences led the author to significant research questions about the experiences of the students in the two locations. The photographs give the viewer the impression that the educational experiences of the students attending the vocational school are detrimental to the students' development of autonomy and a sense of identity and self, while it seems that the private day school provides an environment much more conducive to the fostering and development of both autonomy and a sense of identity and self. The study makes a concrete connection between the disparities in the socioeconomic background of the students and the implications that these differences might have on future mobility within the existing hierarchical social structure. In the educational process, we also deal with physical space through content within subjects, as well as teaching and learning methods and strategies. The two following articles present examples from the field of visual art education.

In Hypothetical Art and Art Education: The Educational Role of the Method of Hypothetical Artwork Modelling, Jurij Selan reflects on how a hypothetical artwork model can be usefully employed when one wishes to encourage a student to become fictionally involved in the process of artwork creation, thus giving him or her more personal experience of problems that accompany the creating process of a real artwork. A hypothetical artwork is an artwork that exists only as a fictional creation of an art theorist. The explicatory powers of such hypothetical artworks are mainly used by an art theorist to reflect on an art theoretical issue under consideration. Although this kind of argumentation can be deceiving, because it gives a statement of real art on the basis of fiction, it has some important explicatory abilities that can also be put to good use in the art education process. In this case, the construction of a hypothetical artwork is handled as the construction of a theoretical model. When such hypothetical experience is gained, the student can more efficiently learn about the art issue under consideration. In the paper, the author demonstrates how the explicatory powers of the method of hypothetical artwork modelling can be applied to educational practice on an issue taken from colour theory.

Spatial (architectural) design is one of five fields introduced to pupils as part of art education. In planning architectural design tasks one should take into consideration the particularities of the architectural design process and enable pupils to experience space and relationships within it through their own movement. Furthermore, pupils should have an opportunity to play the roles of critical users as well as co-creators or spatial planners. In this respect, a field trip plays a vital role, as it allows pupils to experience architectural space through their own movement, their senses and in a real environment. The architectural experience that these pupils gain differs from their everyday experience of 
moving through space, as the former is based on education and training and helps pupils develop architecture appreciation. These ideas are widely developed in the article The Field Trip as Part of Spatial (Architectural) Design Art Classes by Janja Batič.

How to develop a teaching-learning process sensitive to the differences and commonalities of different cultures living in a space is today a significant question in the field of formal education. This is the main issue in one further contribution in the non-focused part of the journal. The paper Education as a Factor of Intercultural Communication by Grozdanka Gojkov considers alternative constructivism as a possible theoretical starting point regarding intercultural communication within education. The introductory part of the paper deals with Kelly's personal construct theory permeating the arguments in favour of the theoretical research thesis referring to the issue of the extent to which the pluralism of the European culture space interferes with national culture through education. The paper goes on to consider the way pedagogy has been searching for more comprehensive self-observation, self-reflection and self-determination on its way to self-change in order to ensure the freedom of personal action according to contemporary philosophical discussions. The importance of education as a factor of intercultural communication is supported in the article by the outcomes of explorative empirical research, which is an element binding all of the reflections in the text. Finally, key competences for intercultural communication are stated in the paper.

In the third part of the journal, there is a review of the monograph European dimensions of teacher education - similarities and differences (2011) (Valenčič Zuljan, M. and Vogrinc, J. (Eds.). Ljubljana: The National Education Institute and Faculty of Education, University of Ljubljana, ISBN 978-961-253-058-7).

BEATRIZ TOMŠIČ ČERKEZ AND DOMEN ZUPANČIČ

\section{References}

Hauge, A. L. (2007). Identity and Place: A Critical Comparison of Three Identity Theories.

Architectural Science Review, 50(1), 44-51.

Hertzberger, H. (200o). Space and the Architect - Lessons in Architecture 2. Amsterdam: 010 Publishers.

Korpela, K. M. (1989). Place Identity as a Product of Environmental Self Regulation. Journal of Environmental Psychology, 9(3), 241-256.

Tuan, Y. (2003). Space and Place - The Perspective of Experience. Minneapolis: University of Minnesota Press. 